\title{
Evaluation of tourism climate conditions at three stations of Noshahr, Ramsar and Rasht using the physiological equivalent temperature and average predicted polling index
}

\author{
Reza Kakvan' \\ Bohloul Alijani" \\ Mohammad Saliqeh"'
}

\begin{abstract}
Provinces located on the southern shores of the Caspian Sea are one of the most important northern places in the country that have always attracted a great deal of tourists in different seasons of the year due to their various natural, human and historical attractions. Every year, they welcome different tourists. These beaches, while having attractive features for tourists, can also play a vital role in the sustainable development of the natural scenery and conservation area. One of the steps to reach sustainable development is tourism planning. The first step in this area is to assess the tourism climate in the country. In this study, in order to evaluate the conditions of the northern climate of Iran's climate, the meteorological data of synoptic stations of Noshahr, Ramsar and Rasht have been used in a 30-year statistical period divided into three decades of age. The method used to assess the climate of comfort, the physiological equivalent temperature index, and the predicted mean of the survey. The results of this study show that the highest climatic conditions for spending leisure time and tourism activities in this region are two separate periods in the middle of spring (May and June) and the beginning of the fall season (October). The continuation of average heat stress from July to August and cold stress from different periods from November to the end of the winter season is a factor for tourism constraints during these months. For other months, they have relatively good weather conditions in terms of temperature and humidity in a little warm and slightly cool thermal condition. Also, changes over the decades indicate climate change and impact on thermal comfort.
\end{abstract}

Keywords: Climate comfort; Climate change; Tourism; North of Iran

\footnotetext{
I PhD student in Urban Meteorology, Faculty of Geography, Kharazmi University, Tehran, Iran Corresponding Aurhor: rezakakvan@gmail.com

"Professor of Climatology, Kharazmi University, Tehran, Iran - alijani@khu.ac.ir

"'Associate Professor of meteorology, Faculty of Geography, Kharazmi University, Tehran, Iran saligheh@khu.ac.ir
} 


\section{Introduction}

Climate and tourism are very interdependent, so that having favorable climate conditions is one of the potential advantages and potentials for tourism and most travelers pay attention to weather conditions when choosing a place and time of travel (Javan and Molazadeh, 2013). Recognizing the limitations and dangers of climate threatening and awareness of the potential attractions and potentials of climatic features is of paramount importance for any planning at different national, provincial, and urban levels, including tourism (Atai and Hashemi Nasab, 2012). Today, the tourism industry is more complex than an industry in terms of a dynamic global and social phenomenon (Eliot, 1997). The industry forms a large part of the global economy and it's becoming the world's largest and most profitable industry (Zulfiqari \& Heydari, 2010). Tourism is also very important for the economies of developing countries because with the help of financial revenues we can accelerate the development of such countries (Sabzi and Zahraie, 2010). The most basic method of optimal use of natural facilities is firstly their accurate recognition; the next step is to optimize the use of these resources (Tawossi et al., 2008). In tourist destinations, climate as a natural resource has an impact on the tourism industry (Farajzad, 2009). Climate forms an important part of the concept of the environment in which recreation and tourism take shape. Because tourism is a voluntary and voluntary activity, it is often dependent on favorable climatic conditions (Parry, 1993). Human climatic comfort depends on the body's thermal equilibrium with its environment. Understanding the local climate is therefore increasingly important in the study of tourism prospects (Martin, 2014). Temperature, radiation, humidity and airflow are among the most important climatic parameters affecting thermal comfort (Son.Ho et al, 2009). By changing these parameters, comfort conditions will also change. Comfort is a set of conditions that are suitable for at least $80 \%$ of people in terms of heat, or, in other words, in those situations, neither feels cold nor feel warm (Mohammadi, 2007).

Due to the importance of climatic conditions and its impact on human comfort, many studies have been conducted about it in Iran and worldwide and it has attracted the attention of many scholars in different parts of the world and Iran, including the following: 
The tourism climate of several cities across the US and Canada showed that; It is the only Los Angeles climate that provides a pleasant climate throughout the year. Whereas the other cities under study have both winters (cold) and summers (warm) conditions (Scot et al, 2004). The results of the study of the importance of climate in rural tourism planning in part of Turkey show that the study area in June, July and August enjoys high climate comfort (Topay, 2007).

In a study of thermal comfort analysis in the classroom of the University of Parijia Italy based on PPD and PET indices and the results showed that the classroom had thermal comfort conditions in the fall and winter seasons (Buratti and Ricciardi, 2009).

Thermal comfort assessment was performed at the railway terminal based on PET index in India and offered suggestions for increasing passenger comfort through the height of roofs and terminal doors (Deb and Ramachandraiah, 2010). Pantava et al investigated mortality in summer 2007 in Athens by examining four biological factors including ASV (true sensitivity status) TS (gyno sensitivity index) DI (discomfort index) and HL (heat sensitivity index), the results showed a very high level of $\mathrm{HI}$ and $\mathrm{DI}$ index, indicating severe heat stress during the last ten days of June and July (Pantava et al, 2010).

In Iran, the first bioclimatic studies of Iran were presented by Ahmad Hossein Adl (1339) with regard to plant and plant biochemical evidence. After this stage, the most comprehensive research is on Habibollah Sabati's study, which deals more with plant bioclimates and the relationship between drought and vegetation. Using Gaussian method, he plotted the ambrothermic diagrams based on temperature and precipitation for these stations using Gaussian method in 2005; it divided Iran into five climatic zones and plotted it (Mohammadi, 1).

Ramezani et al. (2012) study of Rudsar tourism climate using neural pressure index, they concluded that the months of April, May, and June September, October, November and December are suitable for tourism activities.

Investigation of the most appropriate Ray Man model in the form of physiological equivalent temperature (PET) indices, comfort Average Forecast Survey (PMV) and the Standard Effective Temperature (SET) for the study of climate comfort in the North West Azerbaijan province, the results of the above indices showed that PET index provides better 
and more acceptable results than the North Azarbaijan comfort climate (Sari Sarraf et al., 2010). Based on temperature-physiological (PET) index of comfort zone zoning was done in Khorasan Razavi province (Ismaili et al., 2010). Based on physiological equivalent temperature index (PET), tourism comfort climate of four cities of Mashhad, Rasht, Isfahan and Kish was investigated. The results showed that the period of climatic comfort in the studied cities was short and located in two separate periods at the beginning of autumn and spring (Ismaili et al., 2011).

Heidari and Javan (2012) have studied the climate conditions of northwestern Iran using $\mathrm{TCl}$ index and concluded that in January, February and December, travel conditions are not suitable for this region but with spring and fall, biomedical conditions, especially from June to September, are suitable for tourist activity. Aziz Zadeh and Javan (2013) have zoned susceptible climatic zones in northwest of Iran using effective temperature index. The results of their research show that the effective time distribution of temperature is the same as the time distribution of temperature and humidity. The spatial distribution of effective temperature also follows local topography.

Khaje Amiri Khaledi and Salari Fanoudi (2015) in an article entitled Evaluation and Zoning of Tourism Climate Using $\mathrm{TCl}$ Index (Case Study: Baluchistan), Investigates Baluchistan Tourism Climate Status Using TCI Model and they came to the conclusion that April, October, November, December, January, February and March are the best conditions for tourist climate comfort and May, June, June and August are unfavorable.

So it can be said that climate can be an economic asset for tourists. The northern provinces of the country are attracted by many tourists at various local, national and international levels due to the favorable climate, pleasant climate and the existence of art and historical artifacts. But it seems that this important tourism destination, like other important tourism destinations of the country, has grown unevenly and without a plan in recent decades which can achieve sustainable development by planning tourism development and tourism policy making and achieving this requires working with the right management to attract domestic and foreign tourists from the perspective of income generation and job creation with cultural background. In order to develop tourism in this 
region, it is necessary to specify the appropriate times and places for the presence of tourists and one of the most important needs of tourists is the knowledge of climate and favorable weather conditions for tourism, In this study, it is attempted to investigate the capabilities of the Riemann model.

\section{Methodology}

Comfort climatic conditions are usually expressed by indicators in which a set of anthropological, anthropogenic and environmental elements are involved. These indicators provide climatic data in a way that reflects people's response to the climate and include numerical classification ranging from very appropriate to inappropriate. These indices make it easier to interpret the complex effects of atmospheric elements than human comfort and make it possible to compare different locations from a comfort climate point of view. An ideal indicator should be composed of three physical aspects (such as rain and snow, etc.), physiological) such as air temperature (and the psychological aspect) of clear sky. In addition, the balance of energy between the body and the atmosphere is also intended (de ferits, 2002). Physiologically equivalent temperature index and predicted mean pollen index are among the most important physiological indices of temperature in which all three aspects are considered and in addition to urban and regional planning studies, especially in determining the thermal component of urban microclimates, they have also been extensively used in tourism meteorological studies to investigate climatic conditions for tourists. In order to determine the appropriate time of tourism in the study area using the Riemann model, first, the required climatic parameters were extracted and evaluated daily by the Meteorological Organization of the country over a 30-year period (1985-2015) divided into three 10-year periods. These parameters include air temperature in centigrade, relative humidity in percent, and wind in meters per second and cloudy sky in okta. In this study, three stations of Rasht, Nowshahr and Ramsar have been used to study the climate of tourism and to identify the temporal and spatial differences of tourism.

The PMV index is a 7-class thermal sensing segmentation that ranges from -3.5 (cold) to +3.5 (warm) zero on this scale indicates a neutral thermal feeling. 
The PET index is one of the most commonly used physiological temperature indices derived from the energy balance equation of the human body. The main advantage of this index is its presentation in units of Celsius, Which makes the results understandable to tourists and tourism planners who may not be familiar with the biologic terminology. In the definition of this method, the rate of light-duty metabolism and the rate of clothing failure are averaged to be $80 \mathrm{~W}$ and 0.9 , respectively. Table 2 shows the threshold values for PMV and PET indices.

Table 1 - PMV and PET threshold

\begin{tabular}{l|c|c|c}
\hline Degree of physiological stress & Thermal sensitivity & PMV & PET \\
\hline Very severe cold stress & very cold & - & - \\
\hline Severe cold stress & Cold & -3.5 & 4 \\
\hline Moderate cold stress & Cool & -2.5 & 8 \\
\hline Low cold stress & A little cool & -1.5 & 13 \\
\hline No stress & Comfortable & -0.5 & 18 \\
\hline Low heat stress & A little warm & 0.5 & 23 \\
\hline Moderate heat stress & Warm & 1.5 & 29 \\
\hline Severe heat stress & too warm & 2.5 & 35 \\
\hline Very severe heat stress & Hot & 35 & 41 \\
\hline
\end{tabular}

As mentioned, physiological temperature indices of PMV and PET can be calculated and evaluated by various methods and equations. In view of the complexity and breadth of the relevant equations, researchers in various specialties have designed and presented suitable computer models and software to calculate these functional indices. One of the most important of these computational models is the Ray Man model used in this study. In this model, after entering the geographical coordinates of the study area (situational variables) and climatic parameters (meteorological variables), effective physiological data, including height, weight, age, as well as variables related to the type of coverage and level of activity provided by default, are entered into the model and the parameters considered 
are calculated. The third and fourth class variables are very different and according to the model recommendation they can be considered as the standard average in society. For example, the coverage can be $0.9 \mathrm{kV}$ and the average activity such as driving is 80 watts. It is noteworthy that there is little difference between the sexes of men and women regarding these variables.

\section{Results}

The north of the country has much potential to attract tourists in terms of diversity, historical, natural, cultural and religious attractions. Identifying suitable and inappropriate climatic periods can lead to the presentation of a tourism time calendar. The results of the monthly analysis of PMV and PET indices are presented in Figures 1 to 6 .

Figures 1 to 3 show the monthly PMV index of the study stations. As you can see, the stations are at the beginning and end of the warm months of the year, with months of favorable climate for tourism. In other words, the months of May, June, September and September are in the comfort zone. The July to mid-September are also relatively warm and other months of the year are classified as cold to very cold in terms of PMV. Based on the numerical values of PMV index, December, January and February with values of -2.8 to -3.5 have cold thermal conditions. March and April with cool PMV of -2.9 to -1.4. May and June are in the range of -0.0 to 0.3 in comfort and climate comfort.

July and August with numerical values of 1.1 to 1.5 have warm thermal conditions. May and October have the highest quality of comfort. Generally, in the north of the country, the cold limit starts in November and lasts until winter. These cold stresses, which last for 5 months, reduce the attractions of the area for tourist purposes. In April, slightly cooler temperatures are relatively comfortable. In such a situation, there is a slight change in the type of coating suitable for the condition. In April, relatively favorable climatic conditions become the highest quality of comfort climate in terms of temperature and humidity. Therefore, early and mid-spring in this region of the country are suitable conditions for tourism however; these conditions reach their highest quality in May. With the onset of July, favorable climatic conditions will lead to a critical period due to the introduction of warm 
masses into the area and an increase in ambient temperature and temperate conditions, and will continue until August. Such bioclimatic pressure has essentially created unfavorable conditions for summer travel.

One of the interesting points about the comfort conditions in this index can be attributed to the differences between different decades. The index shows that the rates vary with respect to climate change in recent decades however, these changes were minor and its value is not much different in the mentioned classification, but this difference is well visible.

Figure 1 - Monthly Classification of PMV Index by Temperature Sensitivity at Noshahr Station

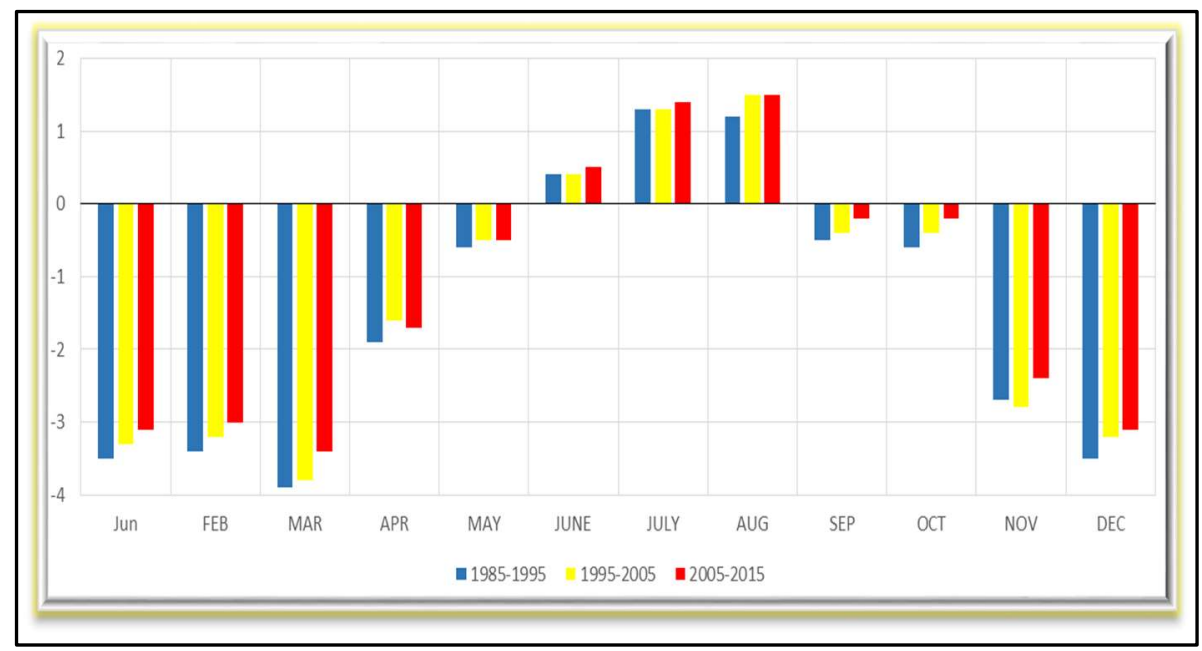

Figure 2 - Monthly Classification of PMV Index by Temperature Sensitivity at Ramsar Station

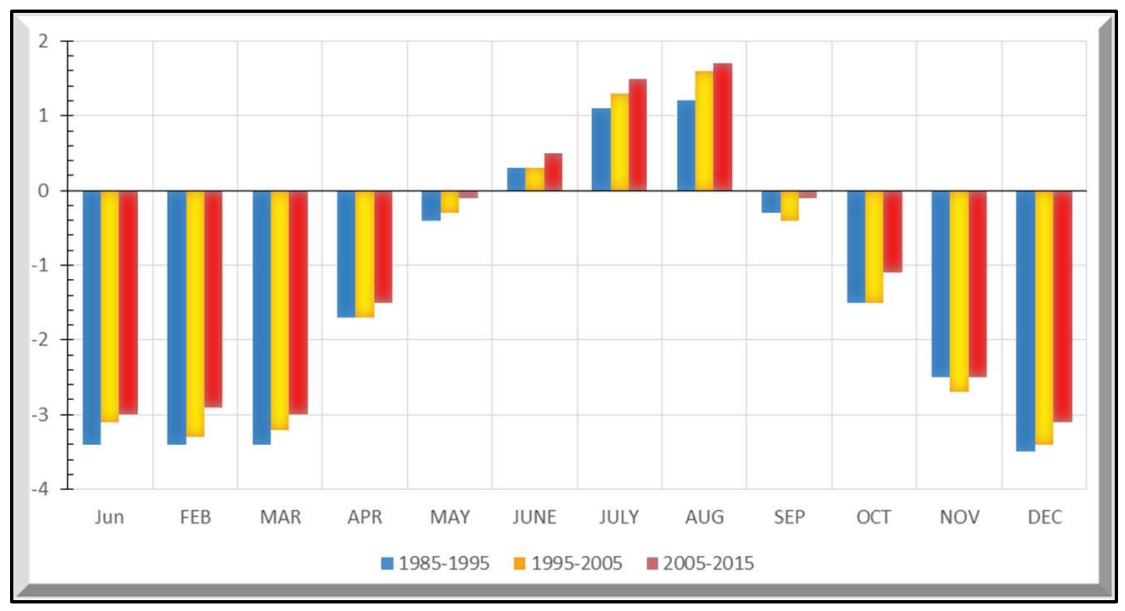


Figure 3 - Monthly Classification of PMV Index by Temperature Sensitivity at Rasht Station

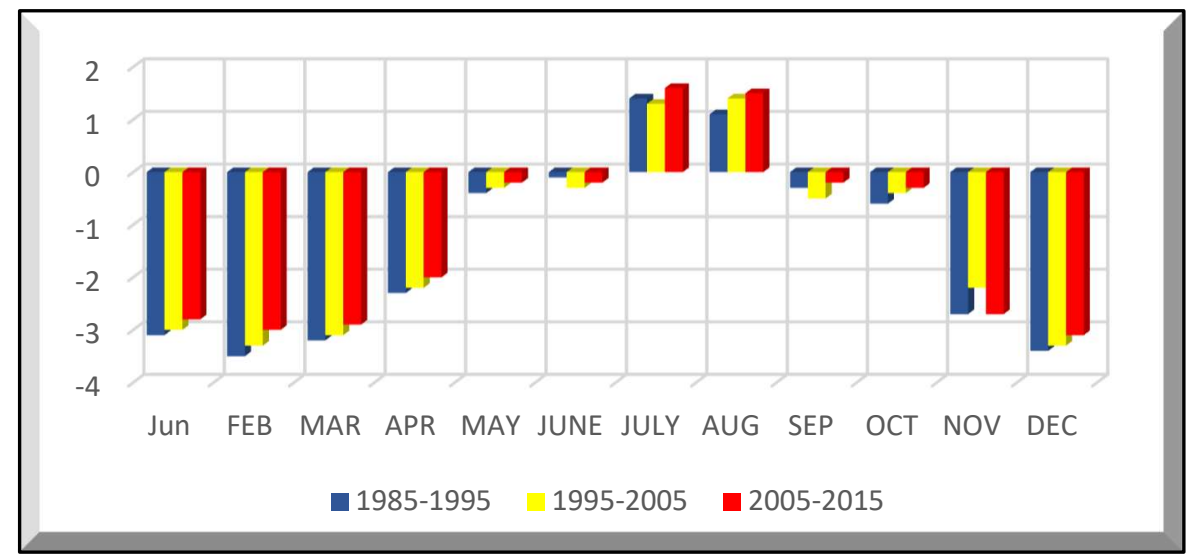

The results of the monthly pet index analysis are presented in Figures 3 to 6 . These results indicate that, based on numerical values of pet, thermal sensitivity varies from cold to hot at the stations under study. January and February enjoy cold temperatures. The months of March and April are numerically cool with 12 to 15 degrees. May and June with numerical values of 18 to 19.5 are in comfortable conditions and thermal comfort. June and August are in the warm thermal range with numerical values of 27-30. September also has a slightly warmer temperature range with a slight decrease in temperature and is comfortable in the Ramsar station. As it was mentioned in the previous section, October is in a comfortable thermal range and human comfort. The other months fall into the cold range due to the cold weather and the influence of Siberian cold air from the north. In fact, from the late autumn to the end of winter due to the dominance of the Siberian and Mediterranean air masses in the region, bioclimatic conditions are subjected to cold stress with varying degrees from severe to moderate. The prevailing cold stress causes the climate to stagnate and it is a factor limiting winter tourism in the north of the country.

Early in the spring, there is little cold stress on the area. This cold stress makes it comfortable with brief arrangements on how to dress. This is also the case in May with low heat stress. Since June, heat stress has gradually developed. This condition first starts with low heat stress and then moderate from July to August. In September, the heat gradually declined and again the heat conditions continued to be slightly warmer by the end of this month. In the autumn, with the air temperature getting more comfortable, the conditions 
will take a different shape. In this season, October has the highest quality of comfort climate in terms of temperature and humidity. By the end of October, cold conditions in the area will gradually prevail so that November will have relatively favorable climatic conditions with little cold stress.

Figure 4 - Monthly Classification of PET Index by Temperature Sensitivity at Noshahr Station

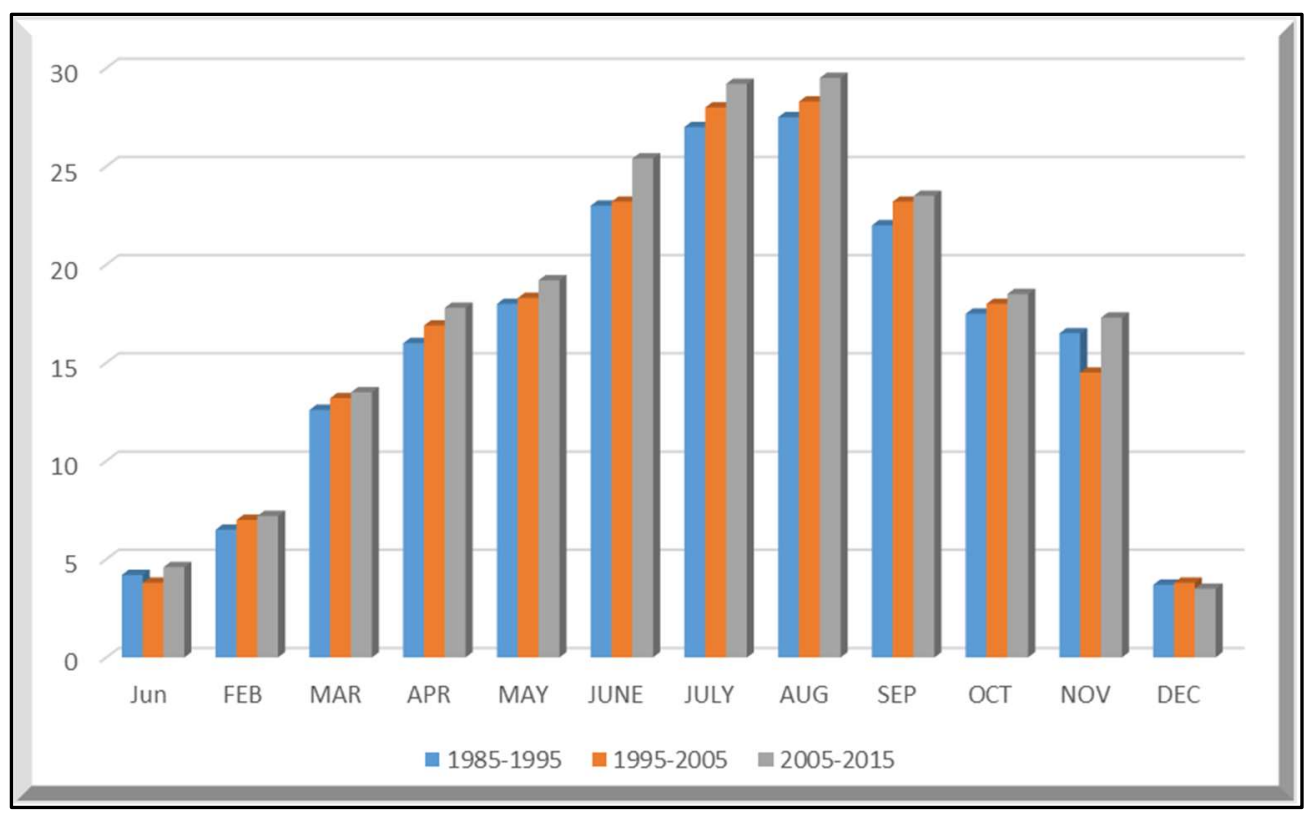

Figure 5 - Monthly Classification of PET Index by Temperature Sensitivity at Ramsar Station

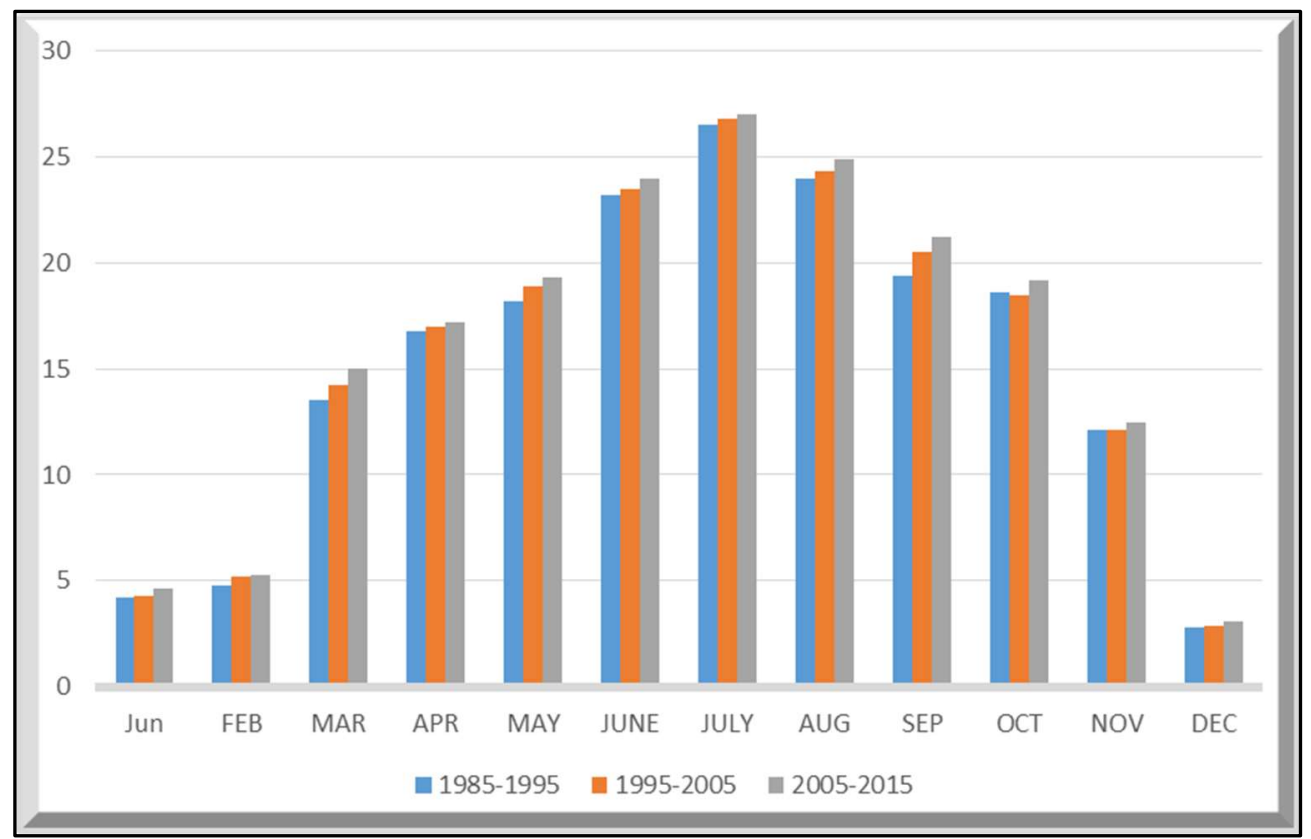


Figure 6 - Monthly Classification of PET Index by Temperature Sensitivity at Rasht Station

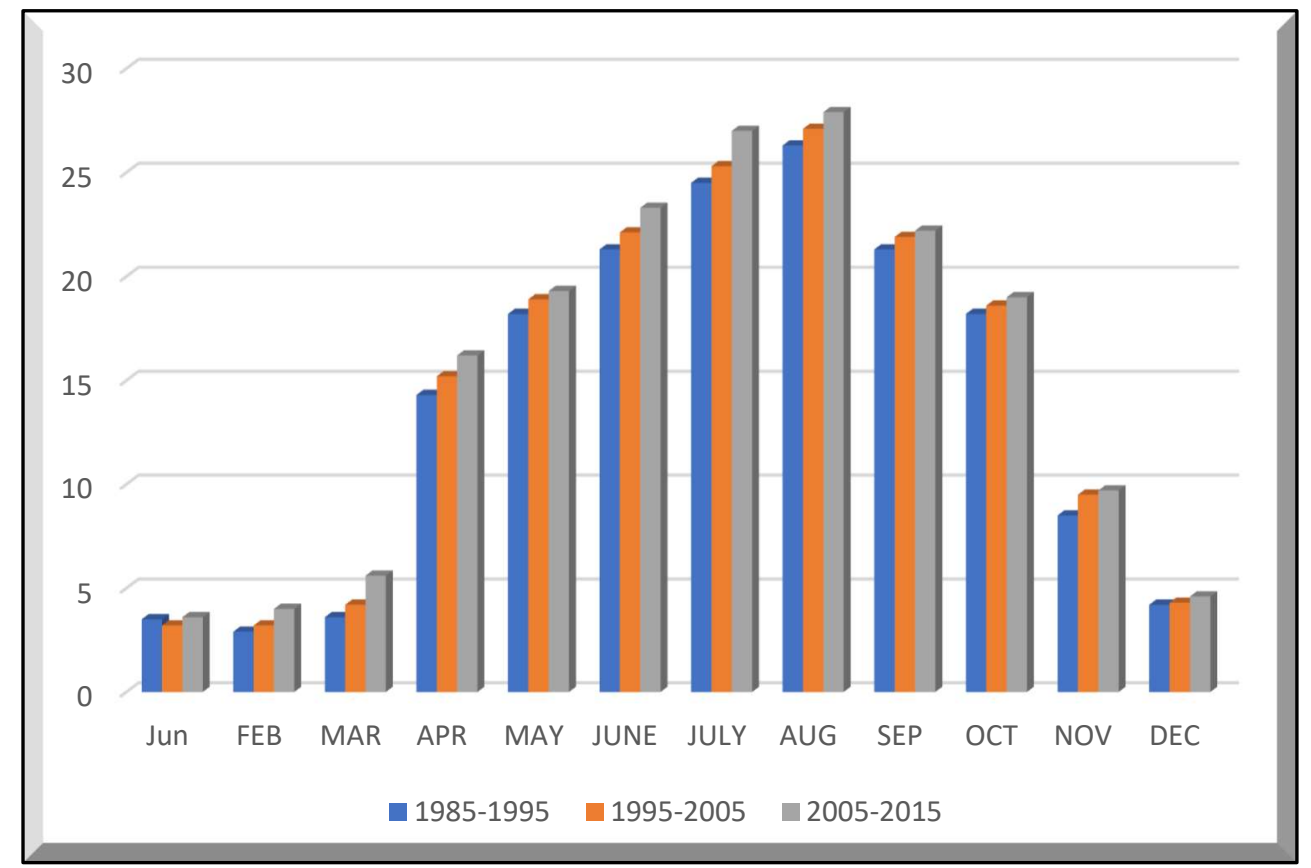

\section{Discussion and Conclusion}

According to the studies, it was found that the study area had favorable climatic conditions based on PET and PMV methods in May, June and October. Therefore, the climatic comfort period of the region is divided into two distinct periods between mid-spring and early fall. The main factors limiting tourism in this area are cold stresses (late autumn to late winter) and heat stresses (late spring to mid-summer). Cold stresses are due to cold conditions and expansion of western systems, and heat stresses are due to high tropical lateral accretion which has put the bioclimatic conditions in crisis, therefore, during this period the study area has less potential for tourism destination. However, the presence of the beautiful Caspian Sea coast, the natural attractions and the surrounding forests partially mitigate this limitation. Khazaei Ali Abad et al., in 2015, by studying different methods of climate comfort at Noshahr station, acknowledged that May and October have good conditions for tourists to be present in this area of the country. The results of this study also confirm their research. Arvin and Shojaizadeh Study the Climate of Shiraz in 2014 Using PET and PMV Indicators and they conclude that these two indicators have a high ability to express the climate calendar. Ramazani Gorabi (2009) in a study aimed at recognizing the 
human bioclimatic comfort potential of Anzali wetland, the results showed that April and May have favorable conditions and bioclimatic comfort, June and August have hot and humid but tolerable bioclimatic pressures and November, December, January, February and March are cold and with mild bioclimatic stimulation. It is also a hot month in June, August and September, in the months of May and October in the conditions of sultry border (number of days associated with sultry phenomenon) and in the months of January, February, March, April, November and December are non- sultry. Torkashvand (2015) evaluated the temporal and spatial climatic comfort of Hamadan province using physiologically equivalent temperature indices and neural indices, they concluded that May, October, and August were most comfortable.

Other results obtained from this study can be found in the small but understandable changes in thermal comfort conditions in this region. Based on the results, it can be said that the climate conditions have changed due to changes in temperature and relative humidity in the region. Although this does not show much variation in the indices used within the month range, it may be possible to clearly see the changes daily. So it can be said that climate change can play an effective role in changing the conditions of comfort. The results of this section of the present study, on the role of climate change, and in particular the effective role of temperature and humidity variables on changes in human bioclimatic zones, are consistent with the results of Givoni's research (1997). But it contradicts the results of Emmanuel's (2005) research that states that climate change has no tangible impact on climate change. Also in internal research the results of this research can be compared with the results of Good Ethics et al. (2010), however, their work in another city and climate model is different but they are consistent with their view that climate change plays an important role in human bioclimatic comfort. This is consistent with their prediction that colder months in the future will have more favorable conditions for human physiology.

Considering that identifying climate potentials and providing the right time calendar is an effective step in enhancing the quality and development of tourism therefore, it is recommended to consider the time of tours, conferences and sports competitions during this period in order to increase the quality and satisfaction of the trip, considering the climate 
comfort in the north of the country. Also, as cold and heat stresses reduce the tourist attractions of this area in winter and summer, it is suggested that the Tourism Organization and other relevant institutions and bodies, in particular tour operators from inside and outside, be more careful and sensitive about the timing and attraction of tourists and as a very important component in their advertising, they place a special emphasis on attracting local and foreign tourists to visit the historical, natural, and cultural attractions of the region in a climate-friendly environment.

\section{References}

Arvin, Abbas Ali, Shojaeizadeh, Kobra. (2014). Evaluation of Shiraz Tourism Climate Conditions Using Predicted Physiological Equivalent Temperature and Average Survey Indicators, Journal of Natural Geography, Seventh Year, No. 26, pp. 87-98.

Attai, Hooshmand and Hashemi Nasab, Sadat. (2011). Investigating the Potential of Tourism in Semnan Province Using PMV Index, Proceedings of the First International Conference on Tourism Management and Sustainable Development with a Tourism Focus on Cultural Relations of Islamic Azad University of Marvdasht, p. 64.

Azizzadeh Varzeghan, Mohammad Reza and Khadijeh Javan. (2013). Zoning of Potential Climate Climates of Northwest of the Country for Development of Tourism Industry Using Effective Temperature Index, Tourism and Future Vision, No. 2

Buratti, C. and P. Ricciardi, (2009) Adaptive analysis of thermal comfort in university classrooms: Correlation between experimental data and mathematical models, Building and Environment, volume 44,pp 674-687.

Deb,Ch. Ramachandraiah, A. (2010). Evaluation of thermal comfort in a rail terminal location in India, Building and Environment, volume 45,pp 2571-2580.

Defeats, C. (2002). Theory, Concepts and Methods in Tourism Climate Research. School of Geography and Environmental Science, the University of Auckland.

Emanuel, R. (2005). Thermal comfort implications of urbanization in a warm-humid city the Colombo Metropolitan Region. Building and Environment, 40(12):1591-1601.

Farajzadeh, Hassan and Andreas Matzarakis. (2009). Quantification of climate for tourism in the northwest of iran, Meteorological Applications 16: $545-555$.

Givoni, B. (1997). Climate consideration in Building and urban Design. First Edition. Publisher London. p 720. 
Heidari, Hassan and Khadijeh Javan. (2012). Evaluation of Climatic Conditions of Northwest of Iran for Development of Tourism Industry, Journal of Tourism and Future Vision, No. 4

Javan, Khadijeh, Malazadeh, Wali. (2013). Surveying the Tourism Climate of Urmia City Using Bioclimatic Indicators, Zagros Quarterly Journal of Urban and Urban Planning, Volume 5, Number 16, pp. 96-83.

Khaje Amiri Khaledi, Chekavak, Salari Fanoodi, Mohammad Reza. (2015). Evaluation and Zoning of Tourism Climate Using TCI Index (Case Study: Baluchistan), First National Conference on Tourism, Geography and Clean Environment, Bu Ali Sina University, Hamadan.

Good Ethics, Faramarz, Guardian, Saeed, Roshan, Gharib, Baghiyan, Hamid. (2010). Investigating the Role and Impact of Climate Change on the Comfort Climate of Yazd City Using the Evans Model. Journal of Geography and Development, No. 8, pp. 167-181.

Khazaei Ali Abad, Mina, Mohammadi, Hossein and Nazarian, Asghar. (2015). Evaluation of Biological Climate Indices Affecting Human Comfort and Its Impact on Tourism Case Study: Noshahr City, Geographical Survey of the Land, Twelfth Year, No. 46, pp. 119-131.

Martin Falk. (2014). Impact of weather conditions on tourism demand in the peak summer season over the last $\mathbf{5 0}$ years, Tourism Management Perspectives, Volume 9, January 2014, Pages 24-35.

Mohammadi, A. (2003). Environmental Planning (Marivan Case Study), MSc Thesis, Faculty of Humanities, Tarbiat Modares University, p. 6.

Mohammadi, Hossein and Basiri, Ali, (2007). Impact of bioclimatic indicators on human comfort assessment. Case of Qom, Journal of Environmental Studies, No. 4.

Pantava,K., G. Theoharatos, A. Mavrakis, M. Sacntamouris. (2010). Evaluating Thermal Comfort Condition And Heat Responses During an extremely hot summer in Athens, Building \& Environment, 46.

Parry, A. H. (1993). Climate, greenhouse warning and the quality of life, progress in physical Geography", 17:354-358.

Ramazani Gorabi, Bahram. (2009). Recognizing the Potential of Human Bioclimatic Comfort in Anzali Wetland, Journal of Natural Geography, Second Year, No. 6.

Ramazani, Bahman and Farajzadeh, Hassan and Roshanak Moradian. (2012). Studying Tourism Climate in Rudsar Using Neural Pressure Index, Journal of Tourism Space, Vol. 1, No. 2. 
Sabzee, Barzoo and Zahrai, October. (2010). The Role of Eco-tourist Attractions in Sustainable Development of Ilam Province Using GIS, Regional Conference on the Use of Natural Geography in Environmental Planning, Islamic Azad University, Khorramabad Branch.

Scat, D. Jones, B. and Macboyle, G. (2004). "Climate, tourism and Recreation", A bibliography University of Waterloo Canada.

Son H. Ho, Luis Rosario, Muhammad M. Rahman. (2009). Thermal comfort enhancement by using a ceiling fan, Applied Thermal Engineering, PP 8422-84.

Tawassi, Taghi et al. (2008). Climatic Architecture of the New School of Isfahan, Geography and Development, No. 11, Spring and Summer.

Topay, M. (2007). "The importance of climate for recreational planning in rural Case Study of Mugla province", In Proceedings of the First International Workshop on Climate, Tourism and Recreation, www.mif.uni-freiburg.de/isb.

Torkashvand, Mohammad Ghasem. (2015). Temporal and Spatial Evaluation of Hamadan's Climate Comfort Using Equivalent Physiological Temperature and Nervous Pressure Indices, Environmental Planning Journal, No. 31, pp. 173-199.

Zolfaghari, Hassan and Heidari, Fatemeh. (2010). An analysis of the human and tourist climate characteristics of the hot and humid coasts of the south of the country by using the physiological equivalent temperature index (PET), Proceedings of the Fourth International Congress, Islamic World Geographers, Iran, Zahedan, University of Sistan and Baluchestan, April, pp. 25-27.

Zolfaghari, Hassan. (2007). Determination of suitable calendars for circulation in Tabriz using physiological equivalent temperature index (PET) and forecasted survey (PMV), Geographical Research, No. 62, pp. 129-141. 